\title{
Energy Efficient Localization through Node Mobility and Propagation Delay Prediction in Underwater Wireless Sensor Network
}

\section{Mamta Nain}

Chitkara University

Nitin Goyal ( $\sim$ er.nitin29@gmail.com )

Chitkara University

\section{Research Article}

Keywords: Autonomous Unmanned Vehicle, Anchor Node, Communication, Node Localization, Ordinary Node

Posted Date: March 17th, 2021

DOl: https://doi.org/10.21203/rs.3.rs-307261/v1

License: (c) (i) This work is licensed under a Creative Commons Attribution 4.0 International License. Read Full License

Version of Record: A version of this preprint was published at Wireless Personal Communications on August 24th, 2021. See the published version at https://doi.org/10.1007/s11277-021-09024-8. 


\title{
Energy Efficient Localization through Node Mobility and Propagation Delay Prediction in Underwater Wireless Sensor Network
}

\author{
Mamta Nain, Nitin Goyal* \\ Chitkara University Institute of Engineering and Technology, Chitkara University, Punjab, India \\ *Corresponding Author: dr.nitingoyal30@gmail.com, nitin.goyal@ chitkara.edu.in
}

\begin{abstract}
The long propagation delay of sensor nodes' messages and flexibility are the mobile target localization scheme's principal tasks in Underwater Wireless Sensor Network (UWSN). As propagation delay is one of the principal aspects, disturbing the time harmonisation of underwater sensor nodes, a long-lasting delay must be assessed and adjusted to attain precise localization. In this article, we suggest an energy-efficient localization scheme based on Mobility and Propagation delay prediction. The system model comprises Surface buoys that drift on the water surface, Anchor nodes which drift at various water depths and Ordinary nodes that are extensively disseminated at different profundity. Anchor node mobility prediction procedure is intended to analyze and record its speed at every localization period. Then, the propagation delay is expected and compensated to attain precise localization. The ordinary nodes make localization, utilizing the expected speed vectors got from the anchor nodes. The replicating outcomes, exhibit that the suggested method increases overall energy efficiency.
\end{abstract}

Keywords: Autonomous Unmanned Vehicle, Anchor Node, Communication, Node Localization, Ordinary Node

\section{Introduction}

UWSN with mobile nodes has gathered an excessive deal of investigation interest because of its several possible applications in the fields of marine science and technology $[1,2]$. Several sorts of Unmanned Underwater Vehicles (UUVs), like AUVs and gliders, may aid UWSN nodes. They consist of aural modems and recognition sensors for addressing several challenges [3]. Precise localization of these devices is needed to confirm the exactness of the data they collect [4]. In UWSN localization process, as shown in figure 1 every sensor node $N_{1}, N_{2}, \ldots$ is responsible to observe nearby region of its surroundings and transmit the collected data to surface buoy represented as $S_{1}, S_{2}, \ldots$ on water surface through multi-hop communication. Surface buoys is gathering this data through acoustic communication link about unidentified nodes and pass this information to onshore sink with the help of surface link and satellite. UWSNs are Three-Dimensional (3D) networks, comprised of precise sensors that depend on aural communication and drift at various depths of sub-aquatic surroundings. These supportive sensors allow various applications like environmental monitoring, underwater survey, adversity preclusion, and disseminated tactical observation. The advanced features of UWSNs help to investigate data gathering, synchronization, localization, target tracking, energy optimization etc. [5]. UWSN success is limited due to inaccessibility of GPS [6], inadequate battery power, restricted bandwidth, channel features like long-lasting propagation delays and high bit rate error [7]. The wireless channel of the network is pretentious by 
the exclusive and challenging atmospheric situational outcomes in great weakening features, restricted bandwidth, frequency distribution, time-varying multipath fading, and the difference in sound speed [8].

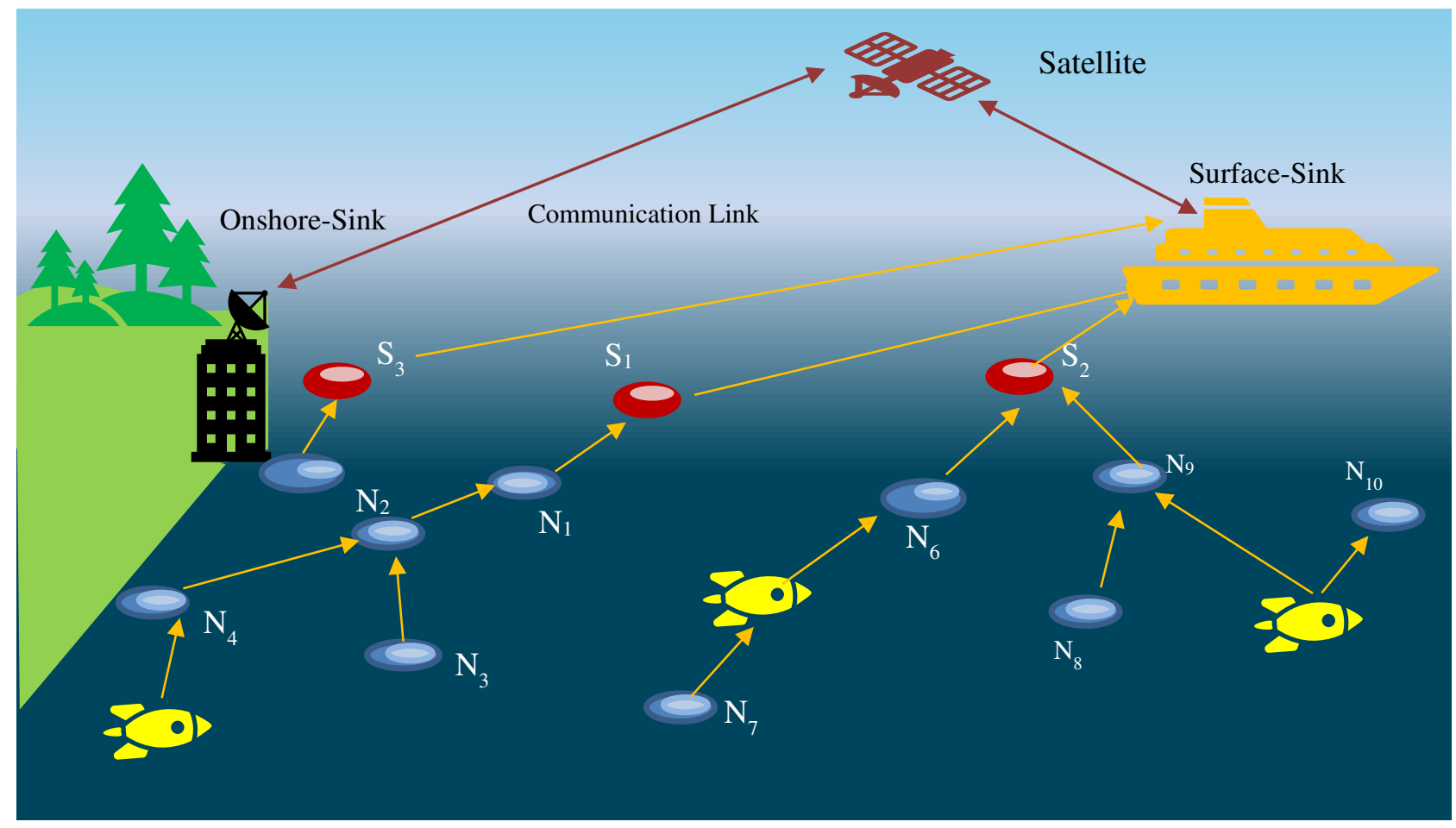

Fig. 1. UWSN Node Localization Architecture

Numerous applications need accurate sensor nodes' locations from where the identified data is transmitted for further processing to create the gathered data expressively [9]. In these circumstances, deprived of knowing the event's position, the data offered by sensor nodes is unusable [10]. So, the exact localization of sensor nodes turns out to be a principal concern for investigators of WSNs. Though sensor nodes' manual disposition is simple and easy, it is impossible for distant and large-scale dispositions [11]. Sensor nodes do not stay in a similar location over time due to passive node flexibility, and therefore, it is hard to organize secure anchor nodes underwater. Hence, the localization systems inside water do not function proficiently in mobile UWSN [12].

Provided the engineering obstacles and monetary charges of battery substitution, the energy-saving localization methods' strategy turns out to be serious about encompassing the network lifespan in UWSNs [13]. Numerous anchor nodes are essential to support a sensor node to discover its location in many node localizations schemes of UWSNs, [14]. These localization procedures' enactment relies on diverse aspects like the nodes' early reference location, number of sensor nodes, anchor nodes, extending method, and anchor nodes' location. This evidence gives inspiration for searching an energy-efficient resolution permitting every sensor node to discover the necessary number of anchor nodes considering localization using topology management [15].

Sensor node's Mobility and propagation delay of messages are the main challenges of mobile-based localization schemes in UWSN [16,17]. As propagation delay is the key feature disturbing the nodes' synchronization, 
lengthy propagation delay should be valued and adjusted to attain accurate localization [18]. Hence the main objectives of this work are:

- To identify the precise location of the unknown sensor node by predicting the mobility pattern of target nodes.

- To achieve a precise time of synchronization by forecasting the long propagation delays.

- The energy of nodes is considered to ensure energy-efficient localization of ordinary sensor nodes.

In UWSN, the localization techniques can be segregated into range-based and range-free [19] categories. To considering the prediction of the mobility of nodes and localization delay, a new robust energy-efficient UWSN localization technique has introduced. Considering these factors for energy-efficient localization is an innovative idea. Overall, paper is organised in different sections, as shown in figure 2.

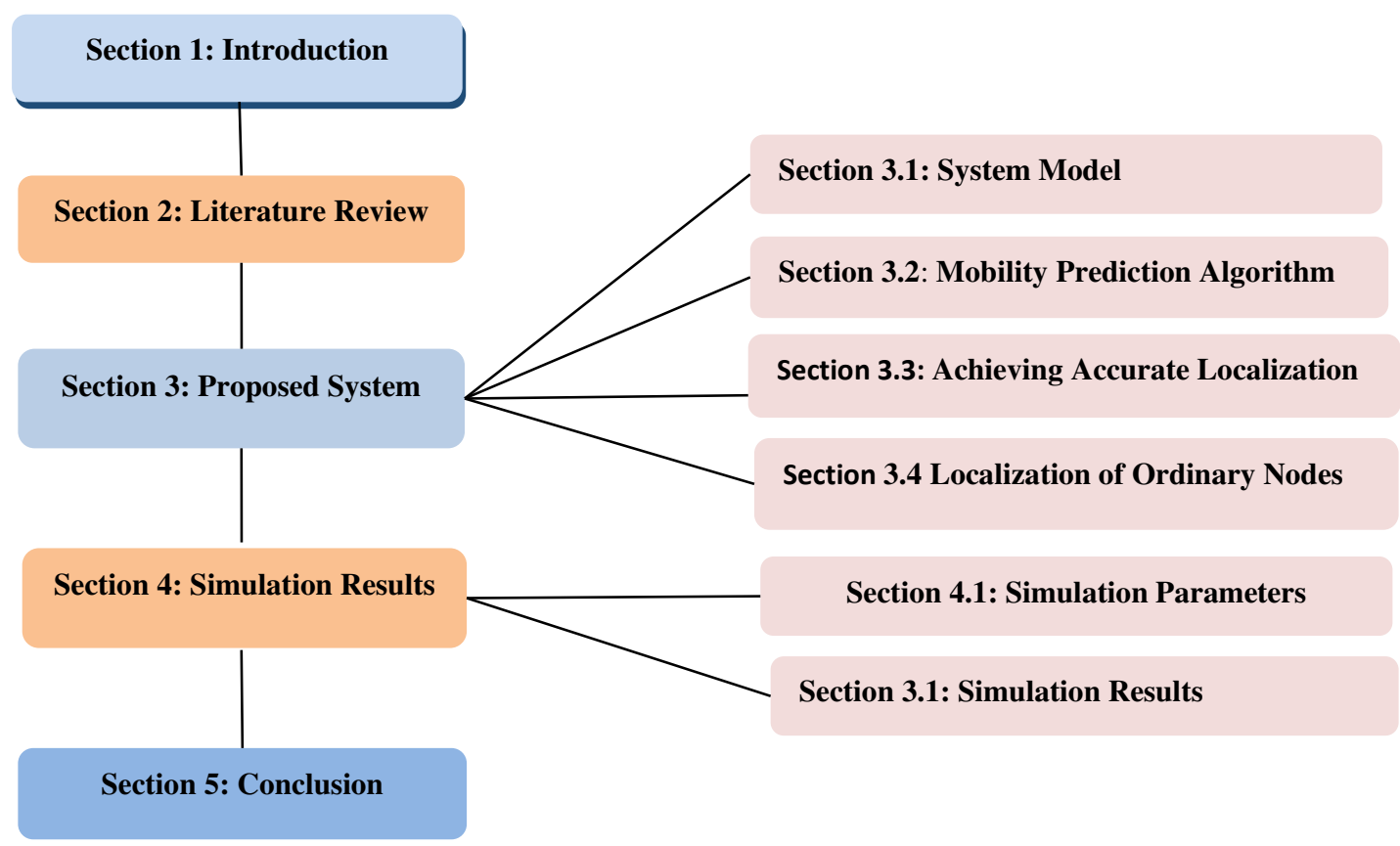

Fig. 2. Structure of the Paper

\section{Literature Review}

UWSN is a growing field of research even though numerous challenges are associated with this network like localization, routing protocol, energy efficiency, etc. Localization is the calculation procedure of the position of the sensor node. If the node's exact position is unknown, then the sensed data might become meaningless, so researchers have proposed several localization algorithms to estimate the sensor nodes' precise locations. Chen et al. [5] have suggested High-accuracy Localization with Mobility Prediction (HLMP) procedure to obtain comparatively precise location estimations. The HLMP procedure uses feature mobility of sensor node and the multistep Levinson-Durbin process to expect upcoming locations. Likewise, they offered a Simultaneous Localization and Target Tracking (SLAT) procedure to apprise sensor positions founded on dimensions in the time of target following. Replication outcomes validate that the HLMP procedure can considerably increase localization precision with less energy utilization and that the SLAT procedure can also lessen the sensor 
localization fault. Goyat et al. [11] have presented an energy-efficient localization procedure, and the method is proficient in three stages. Initially, the beacon nodes determine their one-hop neighbour nodes with further tone demands and response packets over the MAC layer to evade packets' impact. Next, the revealed one-hop unidentified nodes classified into dual groups, i.e., anonymous nodes with head-on and indirect(ancillary) communication for energy competence. In indirect transmission, the source beacon nodes ahead the data straight to the unidentified nodes. However, in indirect communication, a common beacon node is chosen for conveying which lessens total energy depletion throughout a broadcast, as shown in figure 3. Lastly, the alteration aspect is too familiarised, and localized unidentified nodes progressed into assistant nodes for dropping the localization error.

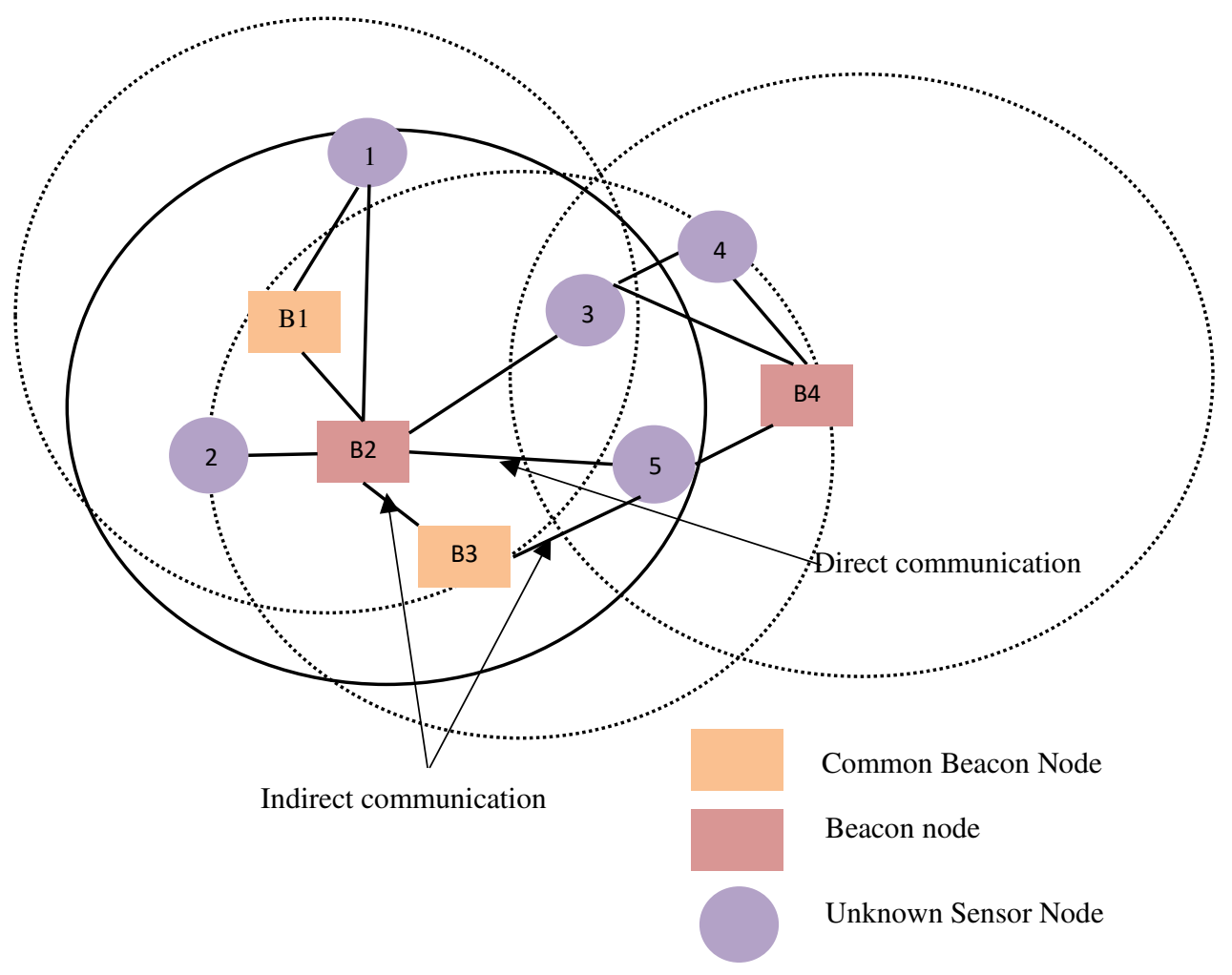

Fig. 3. Nodes with Direct and Indirect Message passing

To examine the distributed exchanges amongst anchor and sensor nodes Yuan et al. [15] presented an EnergyEfficient Localization Algorithm (EELA). A Stackelberg game is used to express sensor nodes, anchor nodes' topology, control issues using their accessible communication chances. In the game, the sensor node performs as ahead, considering the aspects like energy depletion and 'two-hop anchor nodes while the anchor nodes perform as numerous followers, taking into account their capability to find position of sensor nodes and their energy depletion. Guo et al. [20] centred on iterative tracing discussed a mobile target localization technique for UWSN. Four components: first, data gathering, then uneven location assessment is performed, followed by evaluation and decompensation of propagation delay, and finally, the formation of node localization through iteration are recognized in iterative tracing. The divergence of distance approximation because of the supposition that acoustic waves spread besides straight lines in an underwater atmosphere is recompensed by the mobile target localization centred on iterative tracing, and a biased least-squares approximation technique is utilized to do linear regression. Furthermore, an interacting multiple model procedure is set forth to lessen 
the locating error produced by sensor nodes' flexibility. Nodes' localization and time synchronization assist one another in the iterations to progress both gatherings' precision.

Yuan et al. [21] suggested the Adaptive Energy-Efficient Localization Algorithm (Adaptive EELA) to allow energy-efficient node localization while adjusting to the active atmospheric variations. Adaptive EELA takes a fuzzy game-theoretic method, whereas the Stackelberg game is utilized to model the communications amongst sensor and anchor nodes in UWSNs and employs the adaptive neuro-fuzzy technique to fix the suitable usage functions. This localization process gets completed in two steps. During the offline phase to train EELA has generated the Adaptive EELA, training data under various network topologies. Anchor node broadcast the wakeup message with minimum transmission energy during the online step to start the localization process. Ullah et al. [22] familiarised beacon nodes and mobile sensor node's localization. Sensor nodes transfer data by utilizing beacons and finally through the surface buoys antenna. Every sensor node is positioned arbitrary and dropped at any depth, and the position of $\mathrm{X}$ and $\mathrm{Y}$ coordinates are not pre-decided. After the disposition of sensor nodes, they identified a fault in localization and the approximation of the precision of localization. Wang et al. [23] proposed a new method Energy Optimised Distributed Localization (EODL), found on underwater mobile anchors. It is a distributed sensor network location method to calculate an unknown sensor node's position without time synchronization and following the beacon signals. Autonomous Unmanned Vehicles (AUVs) are considered mobile beacons. According to AUV migratory path and qualitative analysis, the period between two consecutive AUV signal, the distance between two neighbouring routes and the profundity of AUV dive is considered. AUVs transmits the beacon signals. The unknown sensor nodes monitor these signals and their quantum received in each course. Depending upon the received signal's effective range, the innermost intersection body is defined. Based on the innermost intersecting body's divergent shapes, position coordinates calculated using the EODL method.

Zhang et al. [24] authors presented an algorithm called Movement Prediction Location (MPL). This algorithm gets completed in two steps mobile prediction and node location. The Time of Arrival (ToA) ranging method is used in the node location step to reduce energy consumption and communication overhead. After this dimension reduction process, the optimal secondary node position calculated with Grey Wolf Optimizer (GWO), which less accurate. This step completes the node location process, enters into the node movement prediction stage and during this step, for the prediction window for the node movement model, velocity and position at each point is predicted. Mortazavi et al. [25] proposed a new localization technique called Robust Joint Localization and Synchronization (RJLS), taking stratification consequence for UWSN into consideration. This technique gets cover in five steps. Propagation delay estimation can be improved by the stratification method. For recompensing the sound speed, stratification effect evaluated from linear relationship. Localization precision and time synchronization can be achieved using the iterative approach. Researchers have proposed a variability of underwater localization techniques; few have been discussed in the literature review above. Different localization algorithms were proposed by considering various node localization issues, but UWSN localization encounters several problems and challenges that need to be considered. Energy efficiency, localization delay and precision are the essential factors in the localization technique. In table 1 analysis of different localization techniques is performed. 
Table 1: Analysis of Different Localization Techniques

\begin{tabular}{|c|c|c|c|c|c|c|}
\hline $\begin{array}{l}\text { Sr. } \\
\text { No. }\end{array}$ & Reference & $\begin{array}{l}\text { Node's } \\
\text { mobility }\end{array}$ & Feature & $\begin{array}{l}\text { Technique } \\
\text { used }\end{array}$ & $\begin{array}{ll}\text { Anchor } & \text { node } \\
\text { placement } & \end{array}$ & $\begin{array}{l}\text { Operational } \\
\text { field scale }\end{array}$ \\
\hline 1 & $\begin{array}{l}\text { Chen et al., } \\
2018 \text { [5] }\end{array}$ & Mobile & $\begin{array}{l}\text { Algorithm gives } \\
\text { precise position and } \\
\text { is energy efficient. } \\
\text { SLAT decreases the } \\
\text { error }\end{array}$ & ToA & $\begin{array}{l}\text { Randomly } \\
\text { distributed }\end{array}$ & $\begin{array}{l}1000 * 1000 \\
* 1000 \mathrm{~m}^{3}\end{array}$ \\
\hline 2 & $\begin{array}{l}\text { Goyat et al., } \\
2019[11]\end{array}$ & Stationary & $\begin{array}{l}\text { Provide a precise } \\
\text { and energy efficient } \\
\text { localization } \\
\text { algorithm }\end{array}$ & Range-free & $\begin{array}{l}\text { Randomly } \\
\text { distributed }\end{array}$ & $100 * 100 \mathrm{~m}^{2}$ \\
\hline 3 & $\begin{array}{l}\text { Guo et al., } \\
2020 \text { [20] }\end{array}$ & Mobile & $\begin{array}{l}\text { Consider long } \\
\text { propagation delay } \\
\text { of messages and } \\
\text { mobility of sensor } \\
\text { nodes. Achieve high } \\
\text { localization } \\
\text { accuracy }\end{array}$ & TDoA & $\begin{array}{l}\text { Randomly } \\
\text { distributed }\end{array}$ & $\begin{array}{l}2000 * 2000 * \\
2000 \mathrm{~m}^{3}\end{array}$ \\
\hline 4 & $\begin{array}{l}\text { Yuan et al., } \\
2019[21]\end{array}$ & stationary & $\begin{array}{l}\text { Energy efficient } \\
\text { scheme is proposed } \\
\text { that considers the } \\
\text { environment } \\
\text { changes } \\
\text { automatically. }\end{array}$ & $\begin{array}{l}\text { Topology } \\
\text { based }\end{array}$ & $\begin{array}{l}\text { Deploy on water } \\
\text { surface }\end{array}$ & $\begin{array}{l}2500 * 2500 \\
* 2500 \mathrm{~m}^{3}\end{array}$ \\
\hline 5 & $\begin{array}{l}\text { Ullah et al., } \\
2019 \text { [22] }\end{array}$ & stationary & $\begin{array}{l}\text { More no of anchor } \\
\text { nodes placed help in } \\
\text { precise location of } \\
\text { sensor nodes. Error } \\
\text { and accuracy } \\
\text { achieved using } \\
\text { angle based and } \\
\text { distance-based } \\
\text { localization } \\
\text { algorithm. }\end{array}$ & $\begin{array}{l}\text { ToA and } \\
\text { AoA }\end{array}$ & $\begin{array}{l}\text { Four nodes placed } \\
\text { at vertices of } \\
\text { network }\end{array}$ & $120 * 120 \mathrm{~m}^{2}$ \\
\hline 6 & $\begin{array}{l}\text { Wang et al., } \\
2018 \text { [23] }\end{array}$ & stationary & $\begin{array}{l}\text { AUVs send their } \\
\text { location and signals } \\
\text { to sensor node. } \\
\text { Sensor node } \\
\text { calculate their } \\
\text { position using } \\
\text { intersection of } \\
\text { beacon signals. }\end{array}$ & Range-free & $\begin{array}{l}\text { No anchor node } \\
\text { used }\end{array}$ & $\begin{array}{l}1000 * 1000 \\
* 1000 \mathrm{~m}^{3}\end{array}$ \\
\hline 7 & $\begin{array}{l}\text { Zhang et al., } \\
2020 \text { [24] }\end{array}$ & Mobile & $\begin{array}{l}\text { Using two steps } \\
\text { mobile prediction } \\
\text { and } \\
\text { estimation, location } \\
\text { position node } \\
\text { calculated }\end{array}$ & ToA & $\begin{array}{l}\text { Deployed on sea } \\
\text { floor }\end{array}$ & $\begin{array}{l}100 * 100 * 20 \\
0 \mathrm{~m}^{3}\end{array}$ \\
\hline 8 & $\begin{array}{l}\text { Mortazavi et } \\
\text { al., } 2017 \text { [25] }\end{array}$ & $\begin{array}{l}\text { Hybrid } \\
\text { (Unknown } \\
\text { nodes are } \\
\text { mobile and } \\
\text { anchor } \\
\text { nodes are } \\
\text { stationary) }\end{array}$ & $\begin{array}{l}\text { Underwater } \\
\text { environment's } \\
\text { stratification effect } \\
\text { is measured and } \\
\text { remunerated. } \\
\text { Iterative process } \\
\text { helps in improving } \\
\text { the localization } \\
\text { accuracy and Time } \\
\text { synchronization. }\end{array}$ & TDoA & $\begin{array}{l}\text { Randomly } \\
\text { distributed }\end{array}$ & $\begin{array}{l}1000 \times 1000 \\
\times 300 \mathrm{~m}^{3}\end{array}$ \\
\hline
\end{tabular}




\section{Proposed System}

Since the sea environment is non-homogenous in relations of temperature, pressure, salinity and water currents, UWSN sensor nodes get drifted due to water currents and shipping movement. These movements of sensor nodes cause difficulty in localization. Energy efficiency is another main challenge in UWSN. In this paper, an Energy Efficient Localization scheme based on Mobility and Propagation Delay Prediction is proposed (EEL-MPDP). The system model comprises surface buoys that float on the water, anchor nodes that flow at different profundity and ordinary nodes widely distributed at different water depths. Each anchor node calculates and records its speed during each localization interval $\mathrm{T}$ in the anchor node's mobility prediction algorithm. The propagation delay is then predicted and compensated to achieve accurate localization. The ordinary nodes perform localization using the predicted speed vectors received from the anchor nodes.

\subsection{System Model}

System model is explained with the help of figure 4, which consists of the following types of nodes:

1. Surface buoys (S) drift on sea surface, and get positions estimate by their GPS. They work as 'satellite nodes' in the UWSN architecture.

2. Anchor nodes (A) float at diverse profundity, and these can get their position approximations by directly communicating with the surface buoys.

3. Ordinary nodes $(\mathrm{O})$ are superficial and primarily distributed at different profundity. As these nodes are less-complex sensors, standard nodes can transmit with neighbours only and cannot get their location estimates through surface buoys.

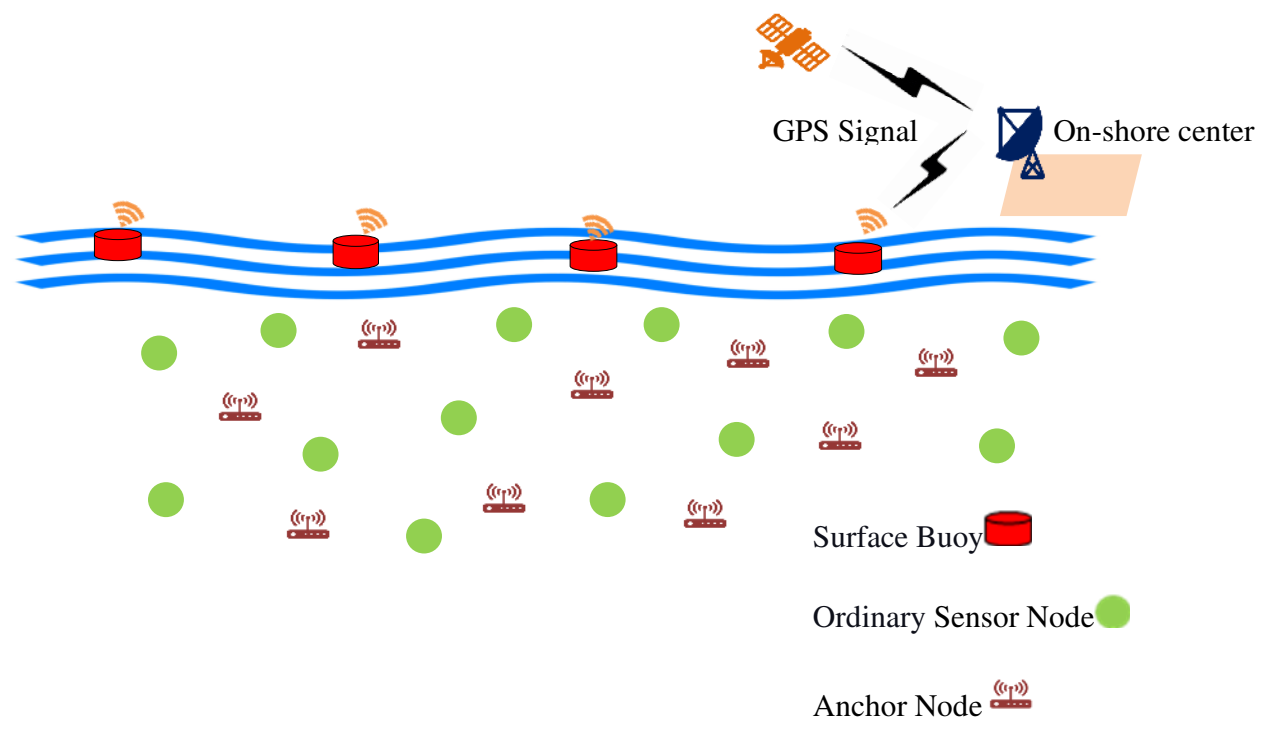

Fig. 4. Underwater Mobile Sensor Network

\subsection{Mobility Prediction Algorithm}

In mobility prediction algorithm of anchor node, each anchor node calculates and keep history (record) of its speed during each localization interval T. The anchor node saves a sequence of speed samples $S_{1}, S_{2}$, ......... $S_{N}$ over time. These predicted speed vectors are considered as references for the ordinary nodes in the localization processes. 
Anchor node calculates and records its velocity during each localization period $\mathrm{T}$ using the equation.

$$
S_{i}=\left(Q_{i}-Q_{i-1}\right) / T+z_{i}
$$

Where, $\mathrm{Q}_{\mathrm{i}}=$ anchor node location at time $\mathrm{i}$

$z_{i}=$ white Gaussian noise due to localization error of an anchor node

Anchor Node saves a sequence of velocities $S_{1}, S_{2}, \ldots \ldots S_{N}$ over time.

To maintain storage space and freshness of data oldest velocity sample will be deleted.

based on earlier velocity value $\left[S_{i}, S_{i-1}, \ldots \ldots, S_{i-(o-1)}\right]^{T}$ and relevant coefficients $\left[\mathrm{e}_{1}, \mathrm{e}_{2} \ldots, \mathrm{e}_{\mathrm{o}}\right]$ anchor node predicts its next velocity using equations (2) \& (3):

$$
\begin{gathered}
S_{i+1}=\sum_{i=1}^{o} e_{i} S_{i+1-j}+\Delta_{i+1} \\
\Rightarrow S_{i+1}=\widehat{S_{l+1}}+\Delta_{i+1}
\end{gathered}
$$

Where, $\mathrm{o}=$ model order

$$
\Delta_{i+1}=\text { prediction error }
$$

Anchor node predicts a greater number of velocities in succeeding periods using the following equations:

$$
\begin{gathered}
S_{i+b}=\sum_{i=1}^{o} e_{i}^{b} S_{i+1-j}+\Delta_{i+b} \\
\Rightarrow S_{i+b}=\widehat{S_{l+b}}+\Delta_{i+b}
\end{gathered}
$$

Where, $b=1,2, \ldots$ B is the length of $\mathrm{S}$.

$$
\left.\widehat{S}=\widehat{\left[S_{l+1}\right.}, \widehat{S_{l+2}}, \ldots, \widehat{S_{l+b}}\right] T
$$

Super node's predicted velocity vectors can be considered as velocity vectors of the entire network and can be found as source to ordinary nodes in finding their position and perform localization.

\subsection{Achieving Accurate Localization}

In this stage, the propagation delay factor is anticipated and recompensed to attain precise localization. The clock skew and clock offset of a node are rationalized to assess exact time synchronization using expected propagation delays. Sensor node can be positioned precisely once the propagation delay is expected and recompensed.

Let $X_{s}=\left(x_{s}, y_{s}\right)$ and $X_{r}=\left(x_{r}, y_{r}\right)$ be the sender and receiver's position coordinates, respectively.

From the source to a destination, the broadcast time of the ray is computed using equation (7):

$$
T=\int_{\mathrm{p}}^{\infty} \frac{1}{\mathrm{c}(\mathrm{p})} \mathrm{dP}
$$


Where, $\mathrm{P}=$ possible path between given end points

$\mathrm{c}=$ velocity along path $\mathrm{P}$

The 2D coordinate system, is represented as per the equation (8):

$$
d P=\sqrt{d r^{2}+d s^{2}}=\sqrt{1+\left(\frac{d s}{d r}\right)^{2} d r}
$$

To symbolize the acoustic ray function, $\mathrm{s}=\mathrm{f}(\mathrm{r})$ is used. It is represented as cartesian coordinates in the plane extended by $\mathrm{x}$ and $\mathrm{y}$ axis.

Let $g$ be the signal's relative mobility distance, then $g$ is derived using equation (9).

$$
g=R V\left(r_{2}+t_{3}-t_{2}\right)+1 / 2\left(r_{2}+t_{3}-t_{2}\right)^{2}
$$

Where, $R V=$ relative velocity

$$
t_{2} \text { and } t_{3}=\text { propagation time }
$$

The relative velocity among two nodes throughout the propagation time will be temporarily neglected. Accordingly, $g$ is derived using equation (10).

$$
g=R V\left(t_{3}-t_{2}\right)+1 / 2\left(t_{3}-t_{2}\right)^{2}
$$

Let $\mathrm{d}$ denote the difference between propagation times.

Let $t_{d}$ be the difference between the $t_{3}$ and $t_{2}$,

Let $\Delta t$ denote the difference between the propagation delays $r_{1}$ and $r_{2}$ and $\alpha$ denotes the angle of the ray, which are given by the following equation

$$
\left\{\begin{array}{c}
\alpha=\frac{1}{2} \epsilon^{e} d^{2} \\
\Delta t=r_{2}+t
\end{array}\right.
$$

The propagation delays $r_{1}$ and $r_{2}$ is estimated using the equations (12):

$$
\left\{\begin{array}{l}
r_{1}=\frac{\sigma \mu-\theta d(R V+\mu)-\alpha}{2 \mu \theta} \\
r_{2}=\frac{\sigma \mu-\theta d(R V+\mu)+\alpha}{2 \mu \theta}
\end{array}\right.
$$

Where, $\theta=$ clock skew

Using these estimated propagation delays, the clock skew and clock offset of a node are updated to estimate accurate time synchronization using equation (13) and (14).

$$
T=u t+v
$$


Where, $T=$ local clock time

$t=$ Ordinary node's reference time

Relative clock skew and offset are represented by $u$ and $v$ respectively

$$
\begin{aligned}
& t_{2}=t_{1}+r_{1} \\
& t_{4}=t_{3}+r_{2} \\
& T_{1}=u t_{1}+v \\
& T_{4}=u t_{4}+v
\end{aligned}
$$

Sensor node can be precisely located after the propagation delay factor is anticipated and recompensed.

\subsection{Localization of Ordinary Nodes}

In this stage, ordinary nodes perform the localization process by utilizing the anchor nodes' speed vectors. Anchor nodes broadcast packets, and Ordinary nodes obtain these packets at localization interludes and then assess their expected velocity vectors in the following expectation interlude. The ordinary nodes then measure the distance to the anchor node $D_{a b}$ using the Time-of-Arrival (ToA) measurement as per equations (18) \& (19).

$$
\begin{aligned}
& D_{a b=} h\left(W^{a}, W^{b}\right)+q_{a b} \\
& h\left(W^{a}, W^{b}\right)=\left(\left(x_{a}-x_{b}\right)^{2}+\left(y_{a}-y_{b}\right)^{2}+\left(z_{a}-z_{b}\right)^{2}\right)
\end{aligned}
$$

Where, $h\left(W^{a}, W^{b}\right)=$ real distance between nodes $a$ and $b$,

$\left(x_{a}, y_{a}, z_{a}\right)$ and $\left(x_{b}, y_{b}, z_{b}\right)$ are Cartesian co-ordinates of node a and $\mathrm{b}$ respectively,

$q_{a b}=$ measurement error.

\section{Simulation Results}

The proposed technique EEL-MPDP's performance is measured using the Aqua-Sim toolkit of NS2. Aqua-Sim is an open-source NS2 based simulator and it is developed for UWSN research [26]. It can effectively handle the attenuation of an acoustic signal, propagation model and packet collisions. It supports 3D deployment and follows an object-oriented design pattern.

\subsection{Simulation Parameters}

Efficient Range-Free Localization Algorithm (EERLA) [11] and Mobile Target Localization, based on Iterative Tracing (ITMTL) [20] scheme, are used to assess the effectiveness of the proposed method. For this, a varying number of sensor nodes are taken as 25, 50, 75, 100 and 125 in the area of $1000 \mathrm{~m} \times 1000 \mathrm{~m} \times 100 \mathrm{~m}$. The system is simulated for 100 seconds. The sensors chosen are with 2 watts of transmitting power and 0.750 watts of 
receiving power. As nodes are mobile, so the minimum and maximum speeds of nodes are taken as three $\mathrm{m} / \mathrm{s}$. The other simulation settings and parameters are tabulated in Table 2.

Table 2: Simulation Parameters

\begin{tabular}{ll}
\hline Parameters & Values \\
\hline MAC Protocol & Underwater Mac \\
Simulation Time & 100 seconds \\
Channel & Underwater Channel \\
Range & $100 \mathrm{~m}$ \\
Routing Protocol & Vector-based Forward \\
Packet Size & $25 \mathrm{bytes}$ \\
Frequency & $25 \mathrm{Khz}$ \\
Initial Energy & 10,000 Joules \\
Transmission power & 2.000 watts \\
Idle Power & 0.008 watts \\
Antenna Type & Omni Antenna \\
Interval & $100 \mathrm{sec}$ \\
Position Update Interval & $0.3 \mathrm{sec}$ \\
Minimum and maximum speed of nodes & 0 to $3 \mathrm{~m} / \mathrm{s}$. \\
\hline
\end{tabular}

\subsection{Simulation Result}

The performance of EEL-MPDP compared with the other two approaches and performance is evaluated based on some QoS parameters like localization error, localization cost, localization delay and residual energy.

Localization Error: This is defined as the difference among the sensor node's actual and the calculated position.

$$
\begin{gathered}
\text { Localization error }=\text { actual position }- \text { estimated position } \\
\qquad \text { loc_err }=\sqrt{\left(x-x_{i}\right)^{2}+\left(y-y_{i}\right)^{2}}
\end{gathered}
$$

Where, $(x, y)$ is the node's actual coordinates and $\left(x_{i}, y_{i}\right)$ represents the sensor node's estimated

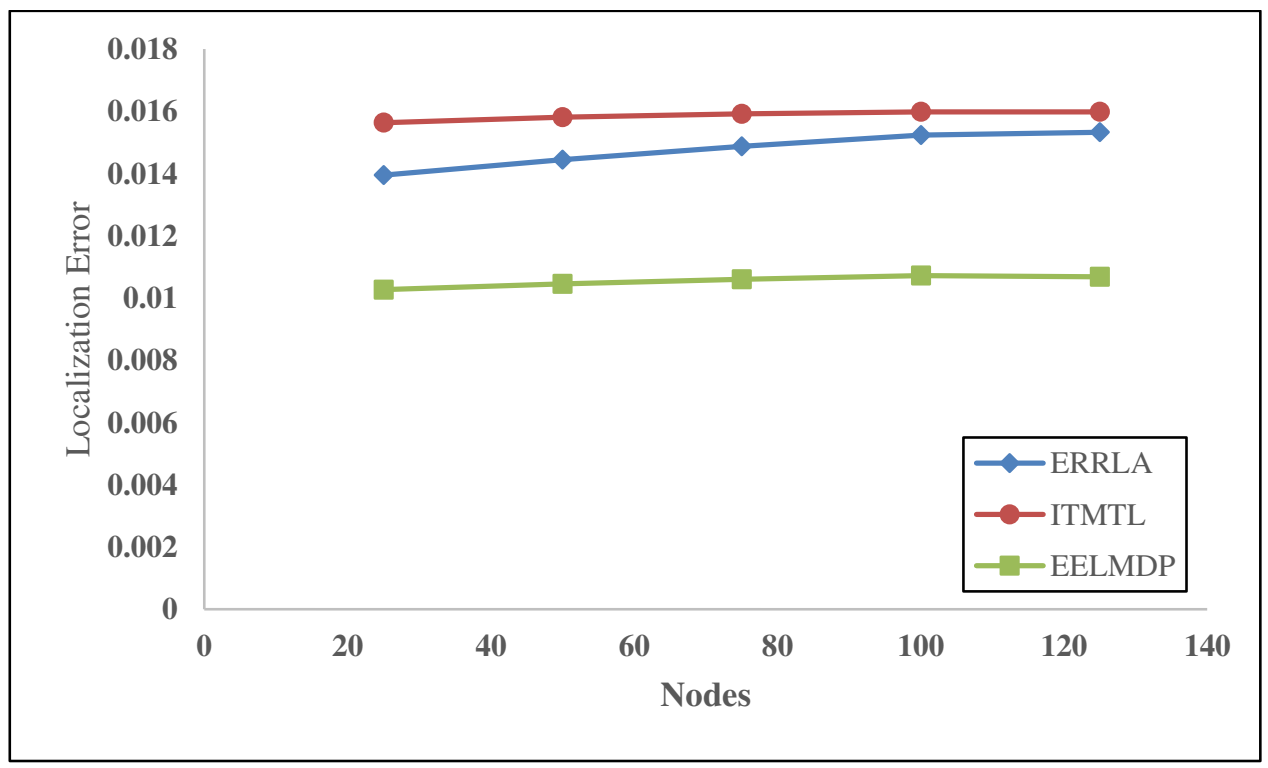

Fig. 5. Nodes Vs Localization Error 
Figure 5 depicts the graphical representation of the results of localization error for varying the nodes. As number of nodes increases from 20 to 140 then localization error of EEMDP ranges from 0.010 to 0.011 , of ERRLA ranges from 0.0130 to 0.0150 , and of ITMTL ranges from 0.015 to 0.015 . Since EERLA have to discover the 1hop neighbours for sending location information, the localization accuracy may be affected during node movement. Moreover, to reflect the node locations, the Neighbour Node List (NNL) has to be updated. Similarly, ITMTL does not predict the node movements and target node positions. But this prediction is possible in case of EELMDP node, hence, the localization error of EELMDP is $29 \%$ less when compared to ERRLA and $34 \%$ lesser than ITMTL.

Residual Energy: Residual Energy: This is the amount of energy that remains at each node to calculate the battery lifetime. This is defined as:

$$
E_{\text {residual_energy }}=E_{\text {total }}-E_{\text {consumed }}
$$

Where, $E_{\text {total }}$ is the total initial energy of a node.

$E_{\text {consumed }}$ is the energy consumed by a node during in-between time interval.

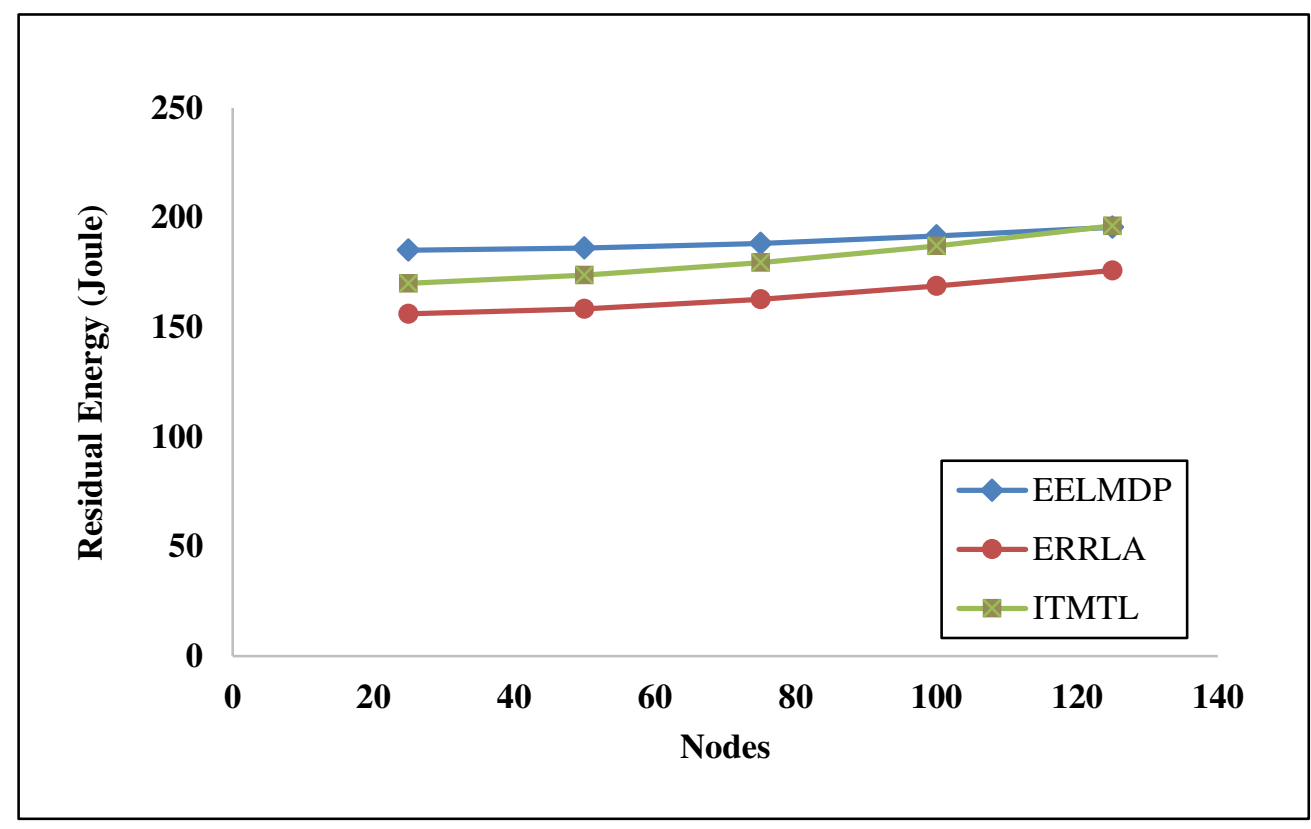

Fig. 6. Nodes Vs Residual Energy

Figure 6 depicts the graphical representation of the results for residual energy for varying number of nodes. The figure illustrates the residual energy of EELMDP ranging from 185.1 to 195.7, ERRLA ranging from 156.1 to 175.8 and ITMTL ranging from 170.0 to 196.2 joules when number of nodes vary from 20 to 140 . The residual energy of EELMDP is $13 \%$ high compared to ERRLA because in case of EERLA for sending location information 1-hop neighbour is discovered. Residual energy of EELMD is 4\% higher than ITMTL because ITMTL has to perform iterative tracing to reduce mobility and this increases the energy consumption.

Localization Delay: It is defined as the time difference between when a sensor node broadcast a request message and when it gets its location. 
Where, Request_ms $g_{\text {time }}=$ Time when a request message gets broadcasted.

Node_loc time $=$ Time when the position coordinates are obtained for a node.

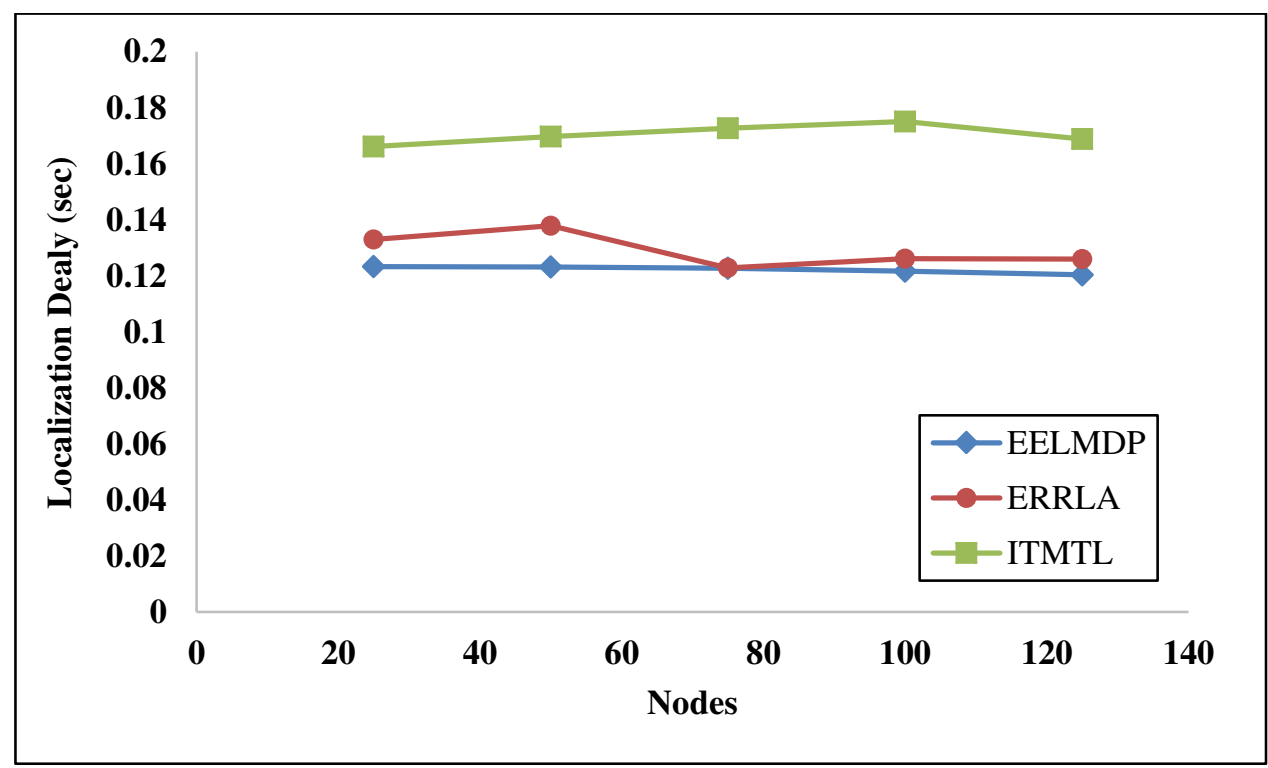

Fig. 7. Nodes Vs Localization Delay

Figure 7 depicts the graphical representation of the results of localization delay for varying the nodes. The figure illustrates the Localization delay with varying number of nodes from 20 to 140. Localization delay of EELMDP ranges from 0.12 to 0.12 , ERRLA ranges from 0.13 to 0.12 and ITMTL ranges from 0.16 to 0.17 . The localization delay of EELMDP is 5\% lesser than ERRLA and 28\% lesser than ITMTL Since ERRLA and ITMTL does not study the propagation delay.

Localization Cost: This is defined as cost to localize the sensor nodes. It is calculated by considering communication overhead, power consumption, pre-deployment arrangement (number of anchor nodes are needed), time taken to localize a sensor node, etc.

$$
\text { Localization Cost }=\text { overhead }_{\text {comm }}+\text { Pow }_{\text {cons }}+\text { Deployment }_{\text {arrangment }}+\text { sensor }_{\text {loc_time }}
$$

Where, overhead $_{\text {comm }}=$ Communication overhead between nodes

Pow $_{\text {cons }}=$ Power consumption in localization

Deployment arrangment $=$ Nodes deployed for localization

sensor $_{\text {loc_time }}=$ Localization time of a sensor node

Figure 8 depicts the graphical representation of the results of localization cost for varying number of nodes. The figure shows that the localization cost of EELMDP ranges from 19 to 15, ERRLA ranges from 25 to 22, and ITMTL ranges from 29 to 26 as number of nodes varies from 20 to 140. Since EERLA needs to discover the 1hop neighbours for sending location information and ITMTL has to perform iterative tracing to reduce the mobility, it will increase the localization cost. Hence, the localization cost of EELMDP is $26 \%$ lesser than 
ERRLA and 14\% lesser than ITMTL. Therefore, the simulation results conclusively confirm that the proposed technique outperforms the other two strategies in energy efficiency, localization error, delay, and localization cost.

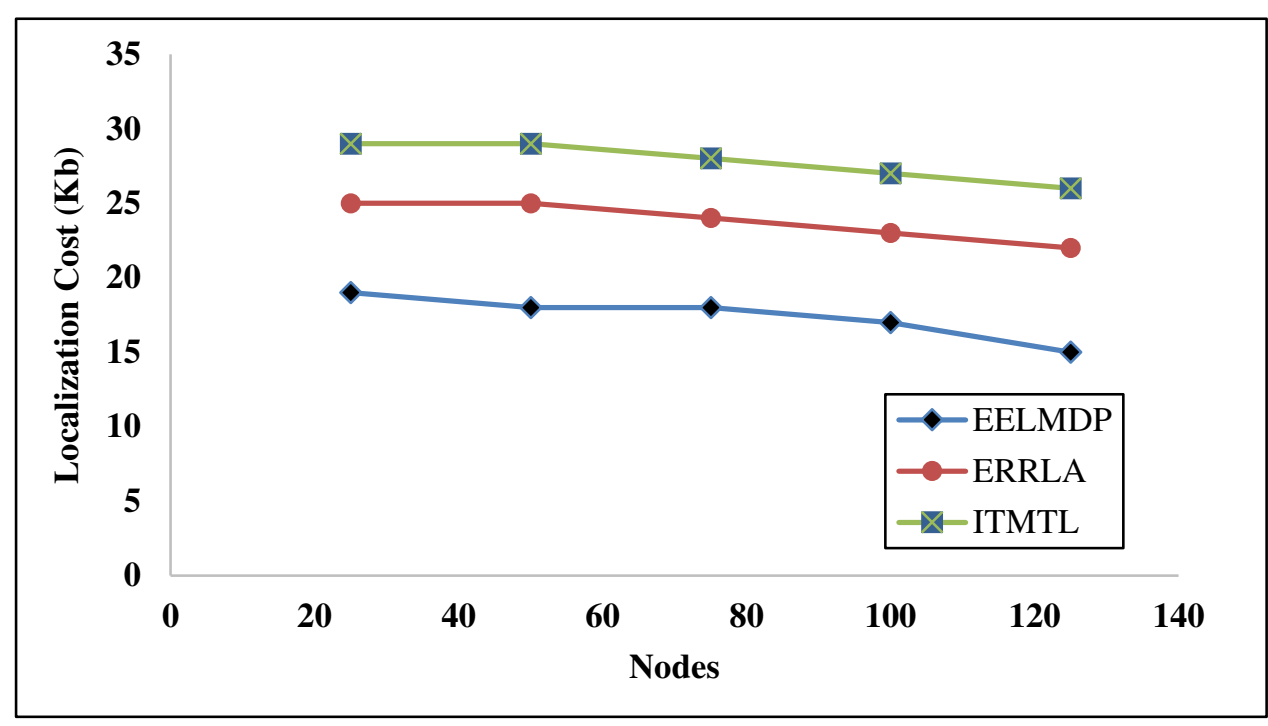

Fig. 8. Nodes Vs Localization Cost

From this study our localization technique can be compared with other techniques based on some Quality-OfService Parameters (QoSP) like energy efficiency, localization delay, localization error and localization cost. In table 3 comparison with other localization techniques is presented.

Table 3: Comparison with other Localization Techniques

\begin{tabular}{llllll}
\hline $\begin{array}{l}\text { Sr } \\
\text { No }\end{array}$ & Scheme Name & $\begin{array}{l}\text { Energy } \\
\text { Efficiency }\end{array}$ & $\begin{array}{l}\text { Less Localization } \\
\text { Cost }\end{array}$ & $\begin{array}{l}\text { High Localization } \\
\text { Accuracy }\end{array}$ & $\begin{array}{l}\text { Low Localization } \\
\text { Delay }\end{array}$ \\
\hline 1. & HLMP & $\checkmark$ & - & $\checkmark$ & - \\
2. & EERL & $\checkmark$ & - & $\checkmark$ & - \\
3. & ITMTL & - & - & $\checkmark$ & - \\
4. & AEELA & $\checkmark$ & - & & - \\
5. & EODL & - & - & $\checkmark$ & - \\
6. & MPL & $\checkmark$ & - & $\checkmark$ & $\checkmark$ \\
7. & RJLS & - & - & $\checkmark$ & $\checkmark$ \\
8. & EEL-MPDP (Proposed & $\checkmark$ & $\checkmark$ & $\checkmark$ & \\
& scheme) & & & & \\
\hline
\end{tabular}

\section{Conclusion}

In this research article, an energy-efficient localization scheme is proposed based on mobility and propagation delay prediction. This algorithm gets covered in three phases. In the first phase, the mobility prediction is estimated for a node; it then forecasts the propagation delay, and then the node's position is calculated. The system model contains different categories of nodes as Surface buoys that drift on the water, Anchor nodes at different water depths and Ordinary nodes widely distributed at different profundity. Anchor node mobility prediction algorithm designed in which each Anchor node calculates and records its speed during each 
localization interval T. Propagation delay is predicted and remunerated to achieve the precise localization. The ordinary nodes perform the localization process and find their position using the expected speed vectors received from the anchor nodes. The proposed technique's simulation results demonstrate improved energy efficiency, lower localization delay and error and reduced localization cost.

\section{References}

[1]. Shams, R., Khan, F. H., Amir, M., Otero, P., \& Poncela, J. (2021). Critical Analysis of Localization and Time Synchronization Algorithms in Underwater Wireless Sensor Networks: Issues and Challenges. Wireless Personal Communications, 116(2), 1231-1258.

[2]. Sahana, S., \& Singh, K. (2020). Cluster Based Localization Scheme with Backup Node in Underwater Wireless Sensor Network. Wireless Personal Communications, 110(4), 1693-1706.

[3]. Wang, S., Chen, L., Hu, H., Xue, Z., \& Pan, W. (2013). Underwater localization and environment mapping using wireless robots. Wireless personal communications, 70(3), 1147-1170.

[4]. Zia, M. Y. I., Otero, P., Siddiqui, A., \& Poncela, J. (2021). Design of a web based underwater acoustic communication testbed and simulation platform. Wireless Personal Communications, 116(2), 1171-1193.

[5]. Chen, H. Y., Liu, M. Q., \& Zhang, S. L. (2018). Energy-efficient localization and target tracking via underwater mobile sensor networks. Frontiers of Information Technology \& Electronic Engineering, 19(8), 999-1012.

[6]. Goyal, N., Dave, M., \& Verma, A. K. (2020). SAPDA: secure authentication with protected data aggregation scheme for improving QoS in scalable and survivable UWSNs. Wireless Personal Communications, 1-15.

[7]. Irshad, M., Liu, W., Wang, L., \& Khalil, M. U. R. (2019). Cogent Machine Learning Algorithm for Indoor and Underwater Localization Using Visible Light Spectrum. Wireless Personal Communications, 1-16.

[8]. Arunkumar, J. R., Anusuya, R., Rajan, M. S., \& Prabhu, M. R. (2020). Underwater Wireless Information Transfer with Compressive Sensing for Energy Efficiency. Wireless Personal Communications, 113(2), 715-725.

[9]. Cayirci, E., Tezcan, H., Dogan, Y., \& Coskun, V. (2006). Wireless sensor networks for underwater survelliance systems. Ad Hoc Networks, 4(4), 431-446.

[10]. Yick, J., Mukherjee, B., \& Ghosal, D. (2008). Wireless sensor network survey. Computer networks, 52(12), 22922330.

[11]. Goyat, R., Rai, M. K., Kumar, G., Saha, R., \& Kim, T. H. (2019). Energy Efficient Range-Free Localization Algorithm for Wireless Sensor Networks. Sensors, 19(16), 3603.

[12]. Ojha, T., \&Misra, S. (2013, January). HASL: High-speed AUV-based silent localization for underwater sensor networks. In International Conference on Heterogeneous Networking for Quality, Reliability, Security and Robustness (pp. 128-140). Springer, Berlin, Heidelberg.

[13]. Ahmed, S., Ali, M. T., Alothman, A. A., Nawaz, A., Shahzad, M., Shah, A. A., ... \&Shaheen, A. (2020). EHUWSN: Improved Cooperative Routing Scheme for UWSNs Using Energy Harvesting. Journal of Sensors, 2020.

[14]. Datta, A., \& Dasgupta, M. (2020). On accurate localization of sensor nodes in underwater sensor networks: a Doppler shift and modified genetic algorithm-based localization technique. Evolutionary Intelligence, 1-13.

[15]. Yuan, Y., Liang, C., Kaneko, M., Chen, X., \& Hogrefe, D. (2018). Topology control for energy-efficient localization in mobile underwater sensor networks using Stackelberg game. IEEE Transactions on Vehicular Technology, 68(2), 1487-1500.

[16]. Saeed, N., Celik, A., Al-Naffouri, T. Y., \& Alouini, M. S. (2019). Underwater optical wireless communications, networking, and localization: A survey. Ad Hoc Networks, 94, 101935. 
[17]. Yan, J., Zhang, X., Luo, X., Wang, Y., Chen, C., \& Guan, X. (2017). Asynchronous localization with mobility prediction for underwater acoustic sensor networks. IEEE Transactions on Vehicular Technology, 67(3), 25432556.

[18]. Awan, K. M., Shah, P. A., Iqbal, K., Gillani, S., Ahmad, W., \& Nam, Y. (2019). Underwater wireless sensor networks: A review of recent issues and challenges. Wireless Communications and Mobile Computing, 2019.

[19]. Beniwal, M., Singh, R. P., \& Sangwan, A. (2016). A localization scheme for underwater sensor networks without Time Synchronization. Wireless Personal Communications, 88(3), 537-552.

[20]. Guo, R., Qin, D., Zhao, M., \& Xu, G. (2020). Mobile target localization based on iterative tracing for underwater wireless sensor networks. International Journal of Distributed Sensor Networks, 16(7), 1550147720940634.

[21]. Yuan, Y., Liang, C., Kaneko, M., Pu, L., \& Fu, X. (2019, August). Adaptive Fuzzy Game-based Energy Efficient Localization in Underwater Sensor Networks. In Proceedings of the ACM SIGCOMM 2019 Conference Posters and Demos (pp. 119-121).

[22]. Ullah, I., Chen, J., Su, X., Esposito, C., \& Choi, C. (2019). Localization and detection of targets in underwater wireless sensor using distance and angle-based algorithms. IEEE Access, 7, 45693-45704.

[23]. Wang, Z., Feng, X., Han, G., Sui, Y., \& Qin, H. (2018). EODL: Energy Optimized Distributed Localization Method in three-dimensional underwater acoustic sensors networks. Computer Networks, 141, 179-188.

[24]. Zhang, W., Han, G., Wang, X., Guizani, M., Fan, K., \& Shu, L. (2020). A node location algorithm based on node movement prediction in underwater acoustic sensor networks. IEEE Transactions on Vehicular Technology, 69(3), 3166-3178.

[25]. Mortazavi, E., Javidan, R., Dehghani, M. J., \& Kavoosi, V. (2017). A robust method for underwater wireless sensor joint localization and synchronization. Ocean Engineering, 137, 276-286

[26]. P. Xie, Z. Zhou, Z. Peng, H. Yan, T. Hu, J.-H. Cui, Z. Shi, Y. Fei, and S. Zhou, “Aquasim: an ns-2 based simulator for underwater sensor networks," in IEEE OCEANS, USA, October 2009, pp. 1-7. 
Figures

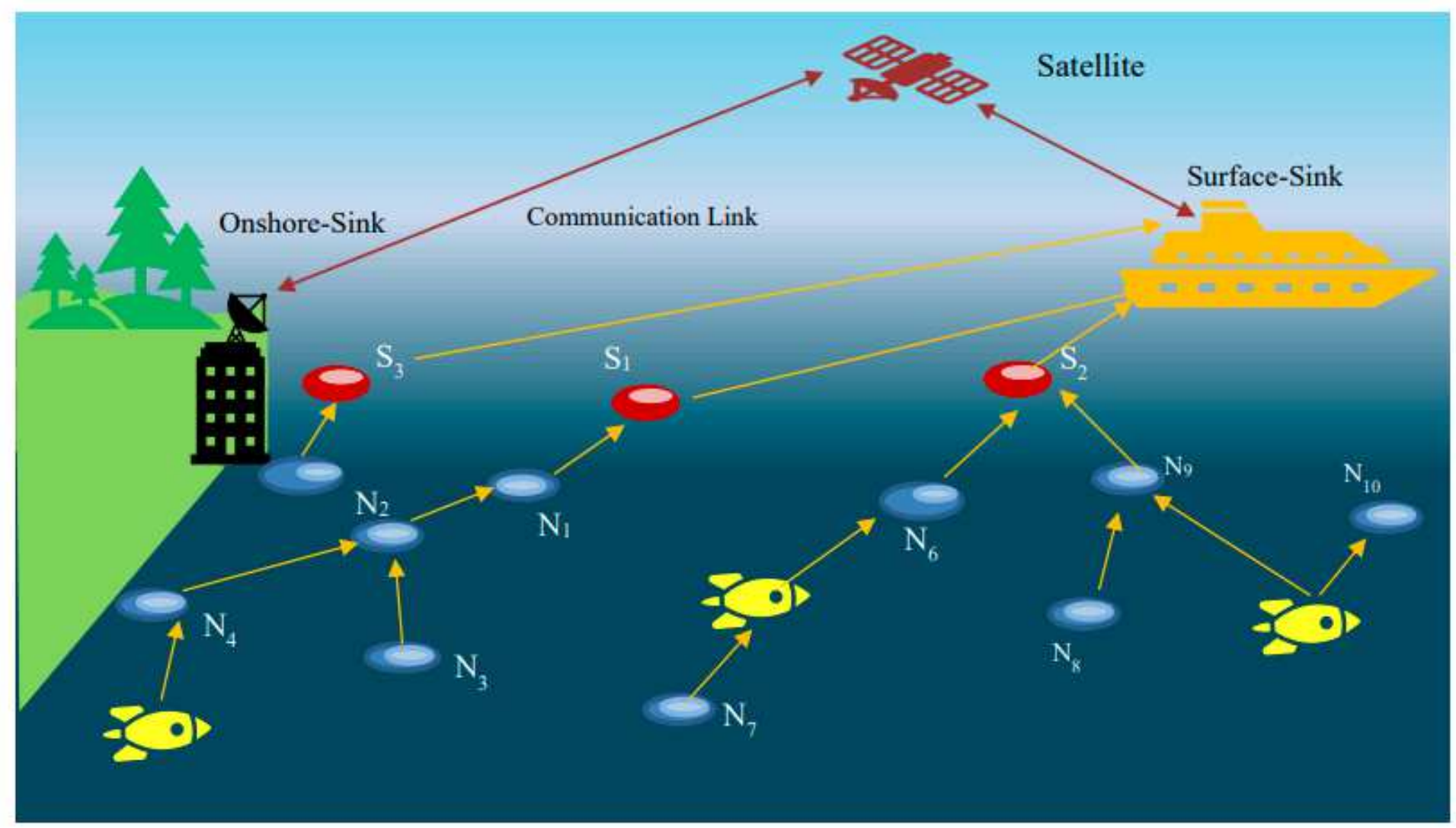

Figure 1

UWSN Node Localization Architecture 


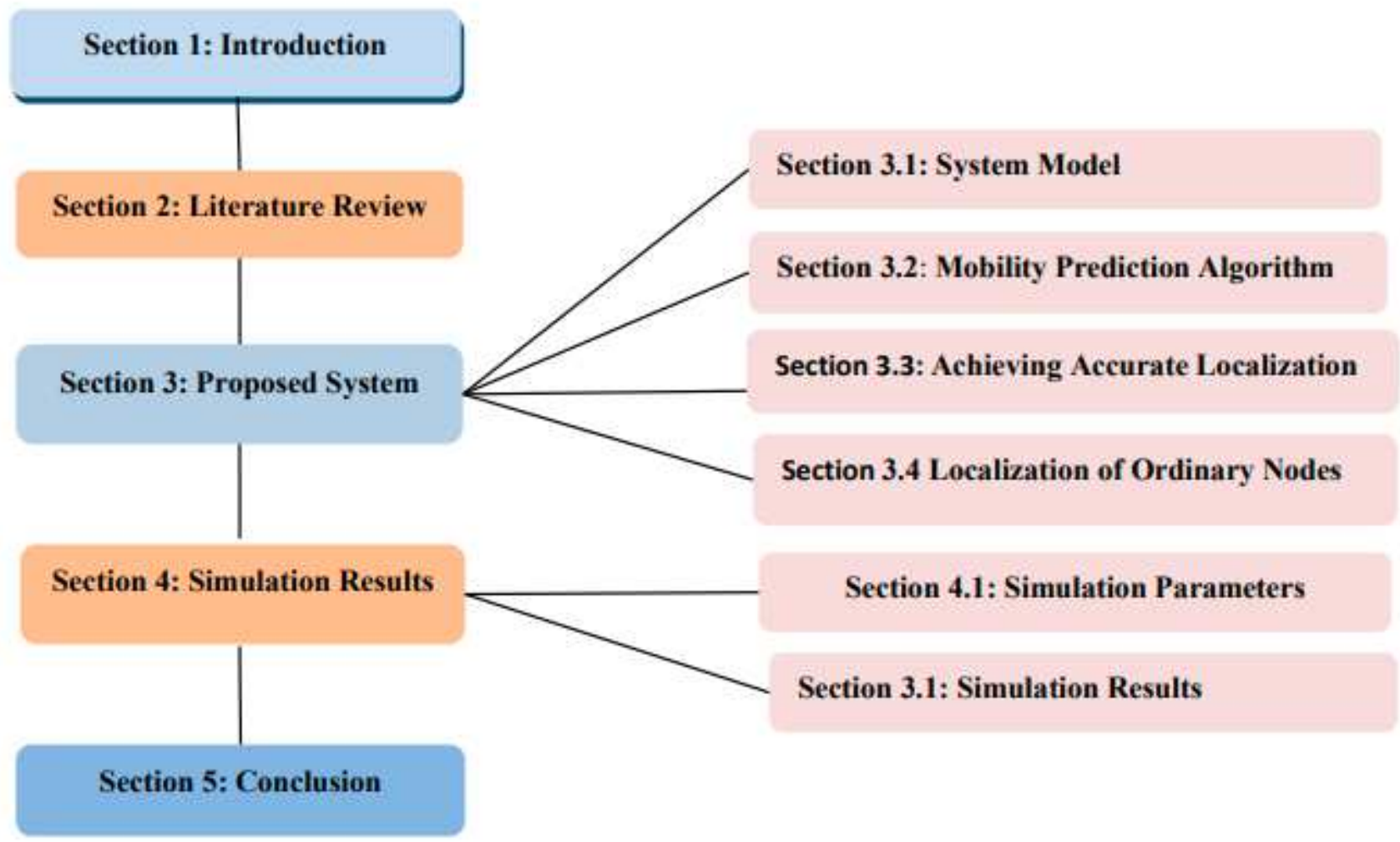

Figure 2

Structure of the Paper 


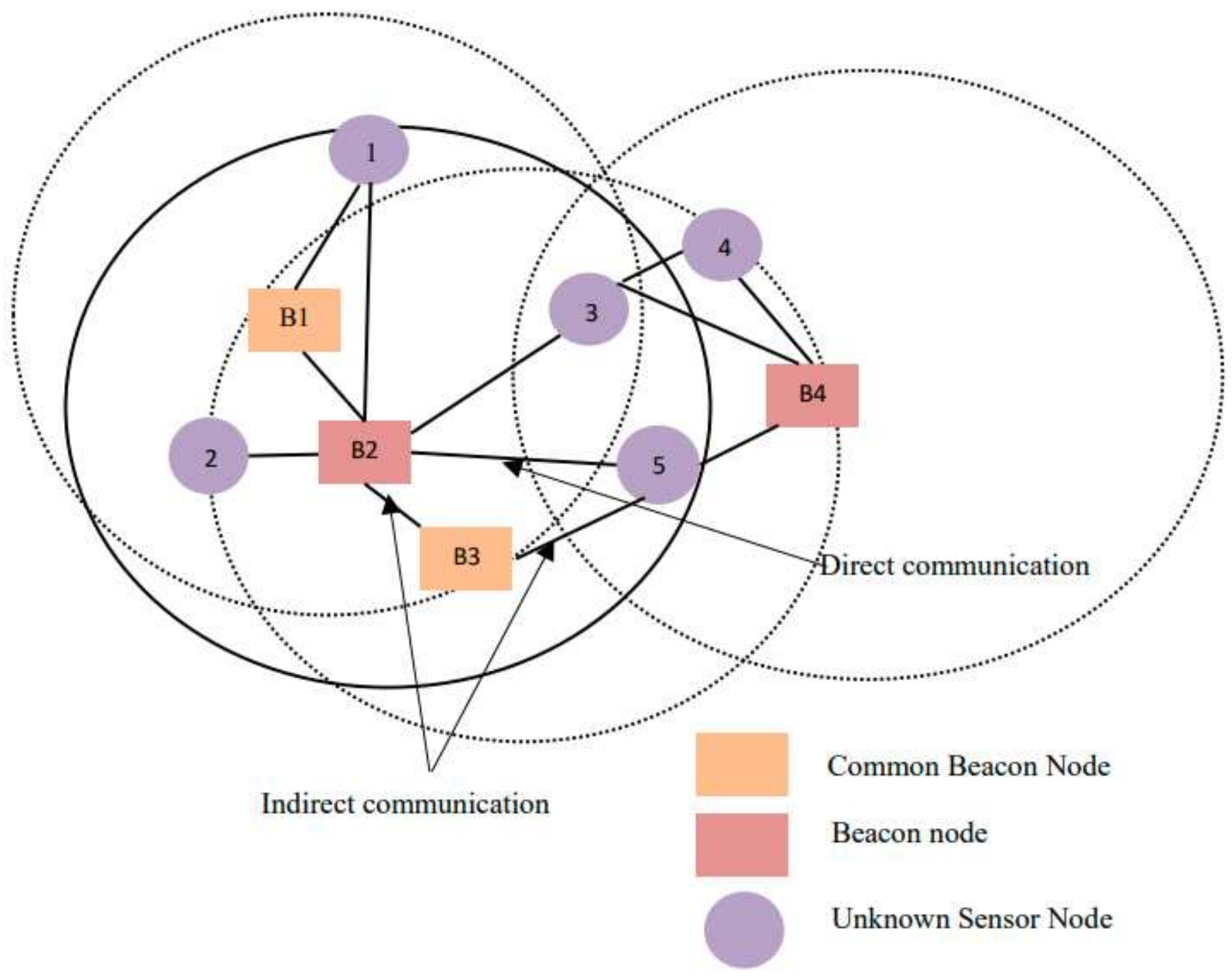

Figure 3

Nodes with Direct and Indirect Message passing 


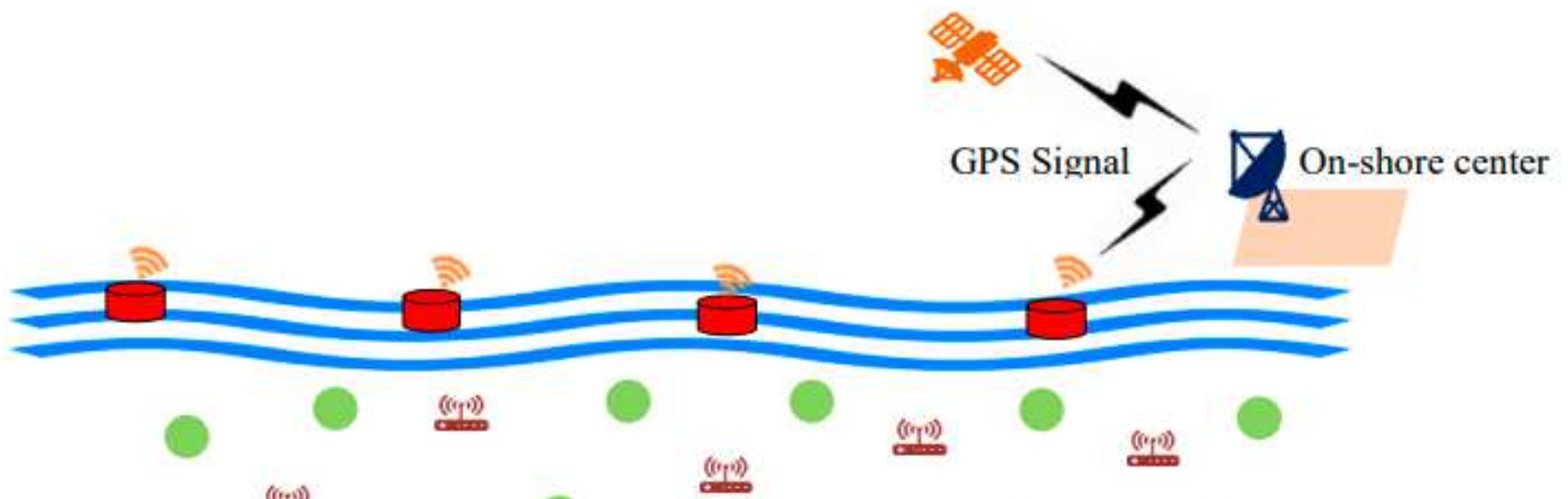
(10iv)

$(\operatorname{cop} 1))$

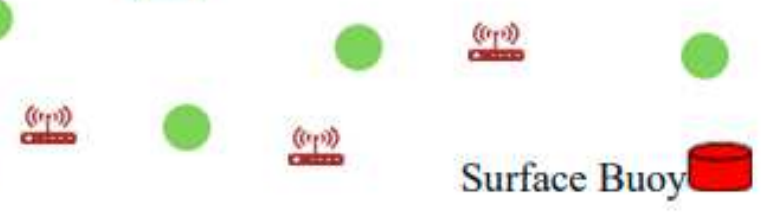

Ordinary Sensor Node

Anchor Node

Figure 4

Underwater Mobile Sensor Network

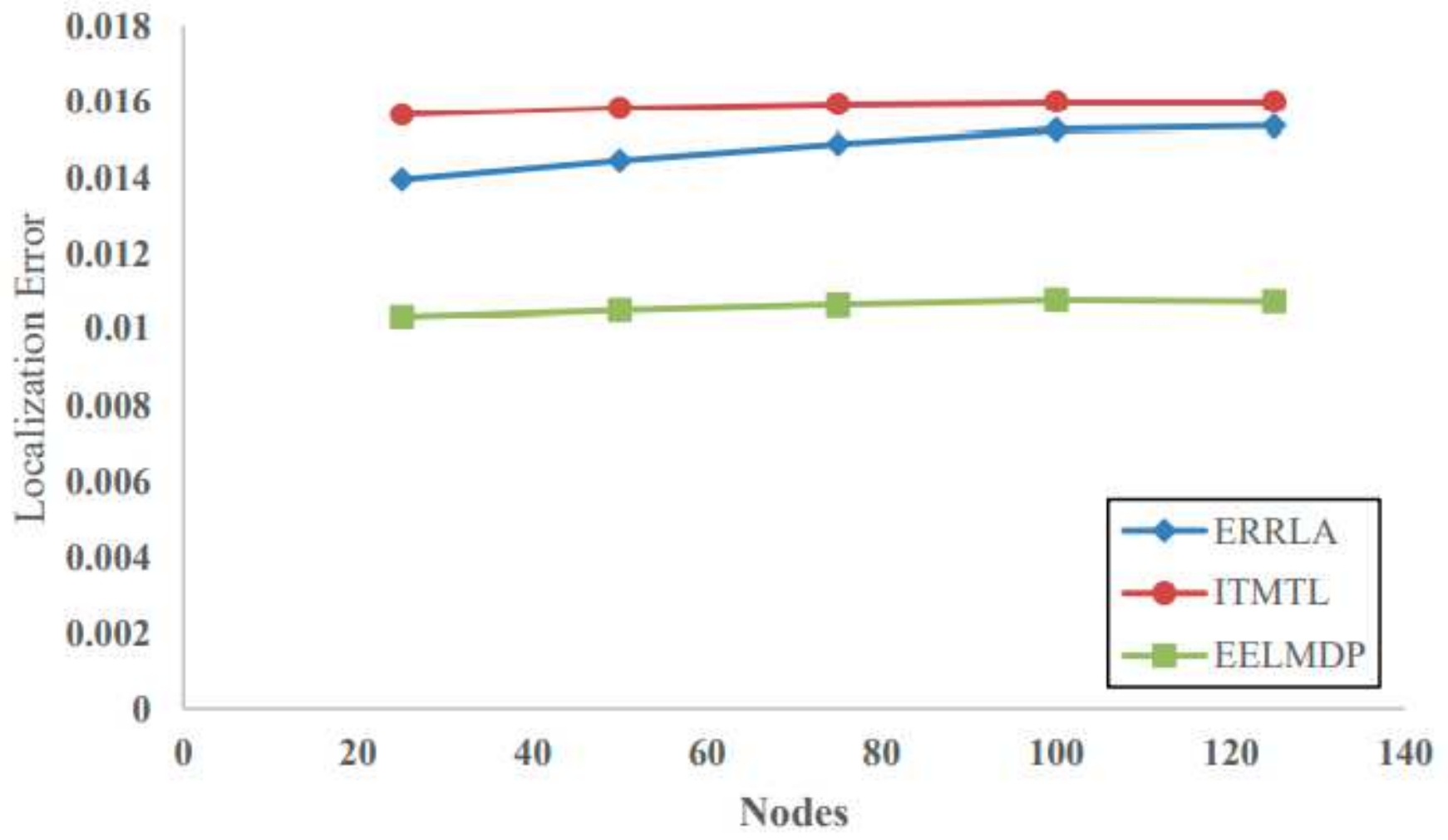


Figure 5

Nodes Vs Localization Error

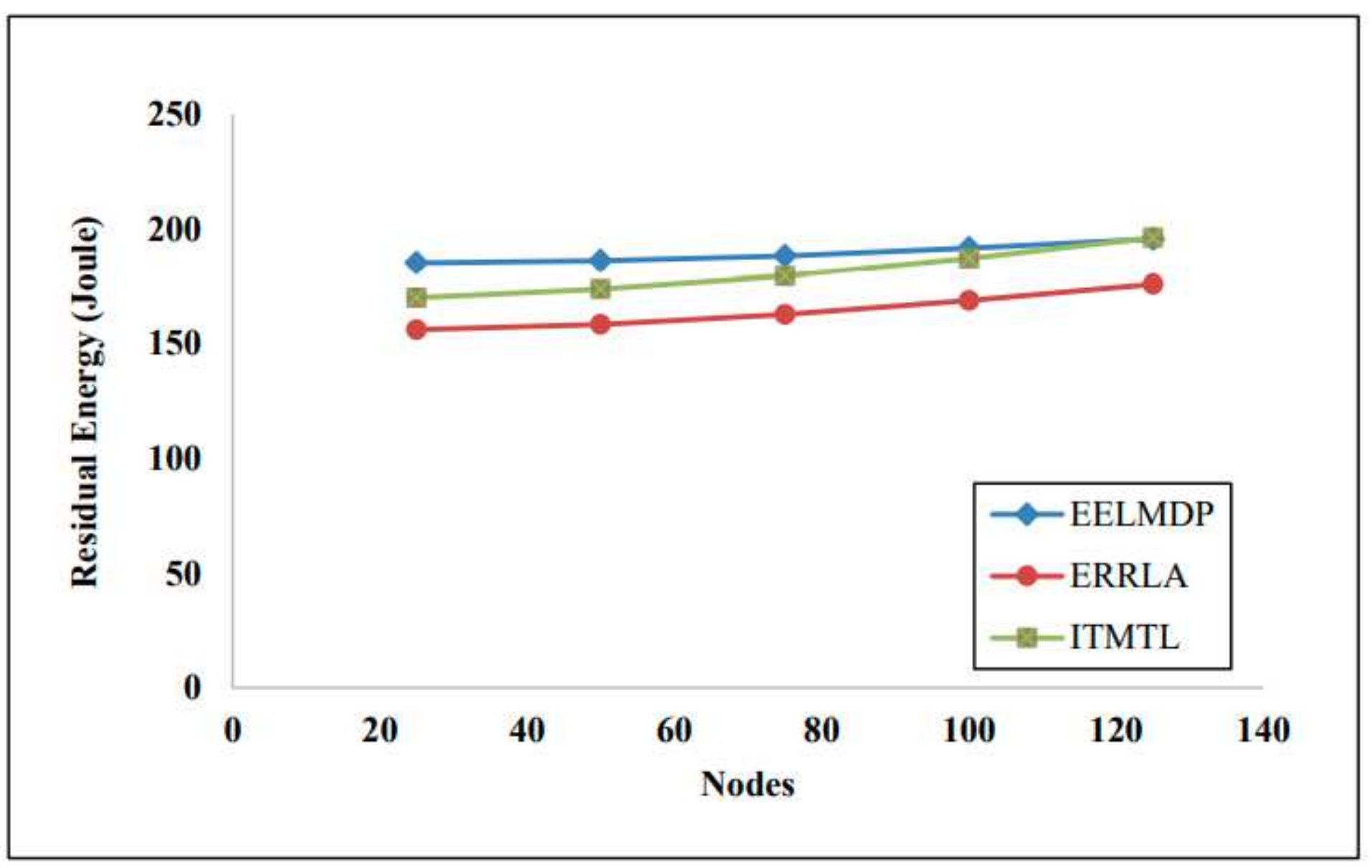

Figure 6

Nodes Vs Residual Energy 


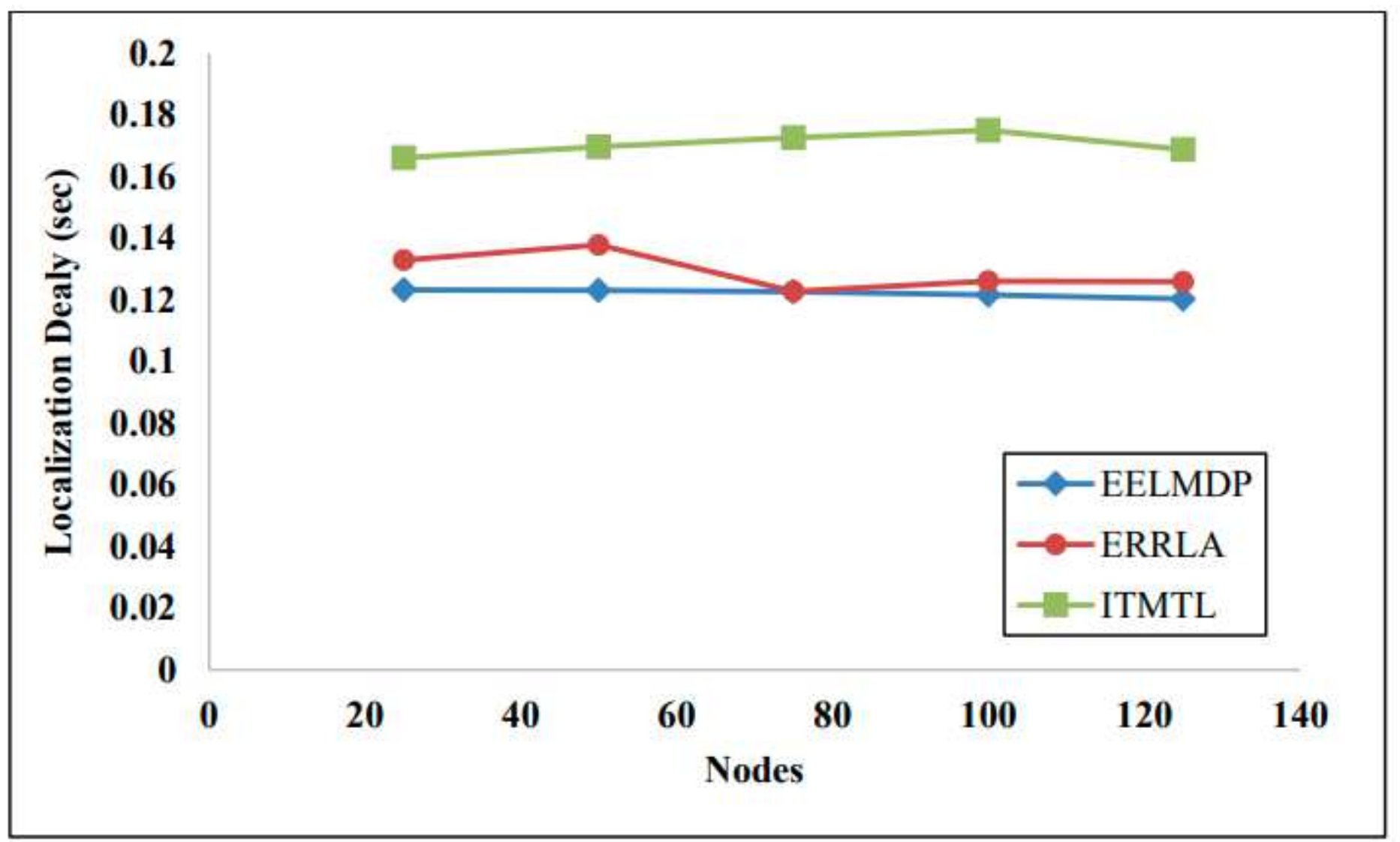

Figure 7

Nodes Vs Localization Delay

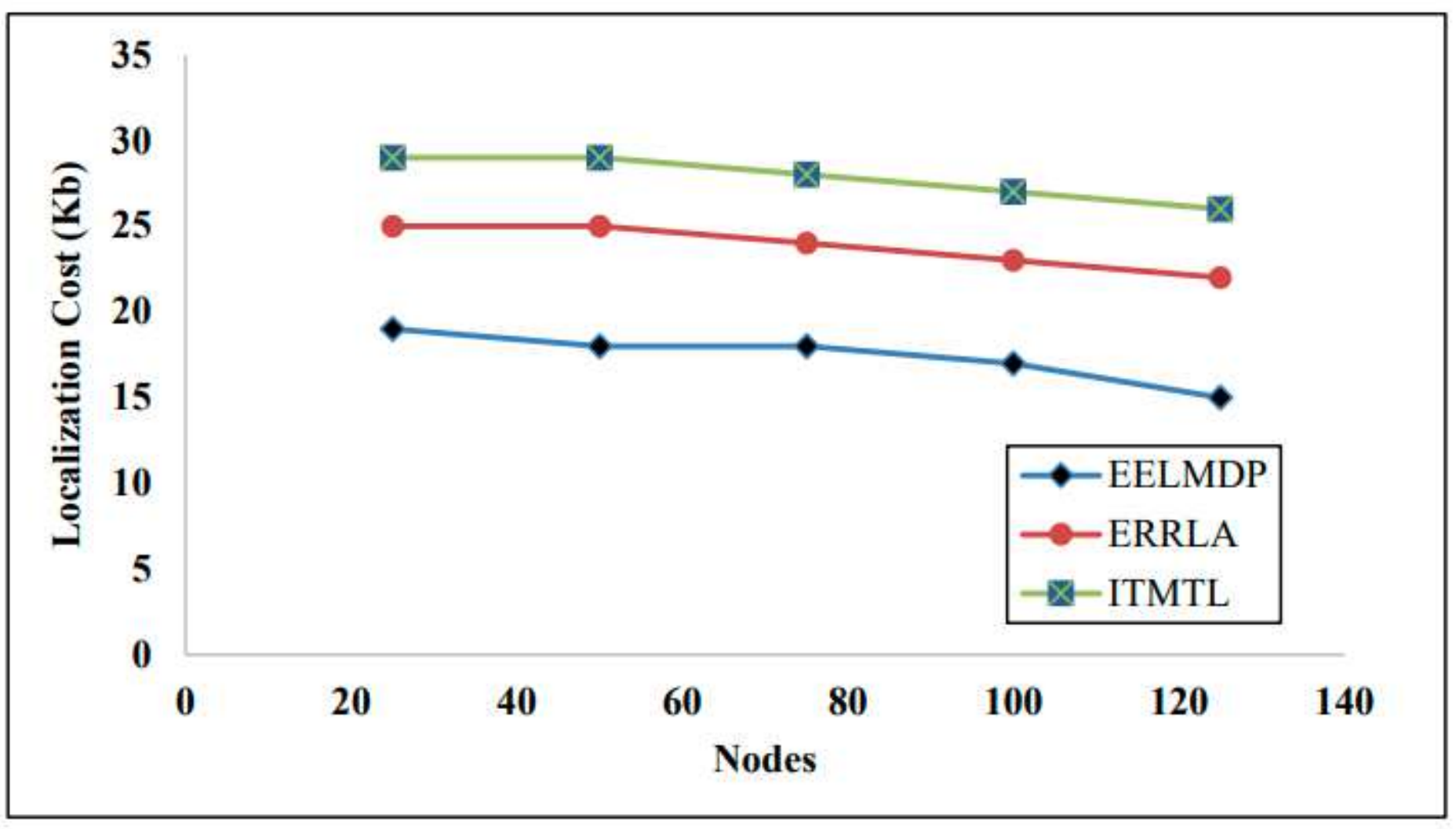


Figure 8

Nodes Vs Localization Cost 